\title{
Shaping Memory Accuracy by Left Prefrontal Transcranial Direct Current Stimulation
}

\author{
Bastian Zwissler, ${ }^{1}$ Christoph Sperber, ${ }^{1}$ Sina Aigeldinger, ${ }^{1}$ Sebastian Schindler, ${ }^{2}$ Johanna Kissler, ${ }^{2}$ \\ and Christian Plewnia ${ }^{1,3}$ \\ ${ }^{1}$ Department of Psychiatry and Psychotherapy, Neurophysiology \& Interventional Neuropsychiatry, University of Tübingen, 72076 Tübingen, Germany, \\ ${ }^{2}$ Department of Psychology, Affective Neuropsychology, University of Bielefeld, 33501 Bielefeld, Germany, and ${ }^{3}$ Werner Reichardt Centre for Integrative \\ Neuroscience, University of Tübingen, 72076 Tübingen, Germany
}

\begin{abstract}
Human memory is dynamic and flexible but is also susceptible to distortions arising from adaptive as well as pathological processes. Both accurate and false memory formation require executive control that is critically mediated by the left prefrontal cortex (PFC). Transcranial direct current stimulation ( $t D C S$ ) enables noninvasive modulation of cortical activity and associated behavior. The present study reports that tDCS applied to the left dorsolateral PFC (dIPFC) shaped accuracy of episodic memory via polaritiy-specific modulation of false recognition. When applied during encoding of pictures, anodal tDCS increased whereas cathodal stimulation reduced the number of false alarms to lure pictures in subsequent recognition memory testing. These data suggest that the enhancement of excitability in the dlPFC by anodal tDCS can be associated with blurred detail memory. In contrast, activity-reducing cathodal tDCS apparently acted as a noise filter inhibiting the development of imprecise memory traces and reducing the false memory rate. Consistently, the largest effect was found in the most active condition (i.e., for stimuli cued to be remembered). This first evidence for a polarity-specific, activity-dependent effect of tDCS on false memory opens new vistas for the understanding and potential treatment of disturbed memory control.
\end{abstract}

Key words: brain stimulation; dorsolateral prefrontal cortex; executive functions; false memory; memory encoding; neuroenhancement

\section{Introduction}

Memory is a dynamic and sometimes creative process. The formation of episodic memories is especially prone to distortions and errors, resulting in retrieved memories being markedly different from those that were initially encoded (Schacter and Slotnick, 2004). These inaccuracies predominantly concern the details of memories instead of their "gist" or general thematic content (Brainerd and Reyna, 2005; Payne et al., 2006), which may be outcomes of an adaptive and economical rather than a defective process (Schacter and Addis, 2007). The preference for memory gist, however, can hamper performance in situations requiring memory precision. Therefore, a balance between the competing demands of memory efficiency, memory accuracy, and its executive control ensures successful learning and behavior. The left dorsolateral prefrontal cortex (dlPFC), in particular,

Received Dec. 23, 2013; revised Jan. 21, 2014; accepted Feb. 9, 2014.

Author contributions: B.Z. and C.P. designed research; B.Z., C.S., S.A., and C.P. performed research; B.Z. and C.P. analyzed data; B.Z., S.S., J.K., and C.P. wrote the paper.

This article was supported by the Werner Reichardt Centre for Integrative Neuroscience (CIN) at the Eberhard Karls University of Tübingen. The CIN is an Excellence Cluster funded by the Deutsche Forschungsgemeinschaft (DFG) within the framework of the Excellence Initiative (EXC 307). B.Z. was funded by the University Hospital Tübingen (fortüne; 2086-1-0). C.P. was supported by the German Research Council (Deutsche Forschungsgemeinschaft; PL 525/1-1) and the CIN (PP 2011_11).

The authors declare no competing financial interests.

This article is freely available online through the J Neurosci Author Open Choice option.

Correspondence should be addressed to Dr. Christian Plewnia, Department of Psychiatry and Psychotherapy, Neurophysiology \& Interventional Neuropsychiatry, University of Tübingen, Calwerstrasse 14, D-72076 Tübingen, Germany. E-mail: christian.plewnia@uni-tuebingen.de.

DOI:10.1523/JNEUROSCI.5407-13.2014

Copyright $\odot 2014$ the authors $\quad 0270-6474 / 14 / 344022-05 \$ 15.00 / 0$ has been shown to exert executive control over the acquisition of episodic memories, presumably by maintaining information required for the formation of useful episodic traces (Rossi et al., 2011; Hawco et al., 2013). However, imaging studies also suggest that the left PFC is critically involved in the formation of both accurate and false episodic memories (Kubota et al., 2006; Kim and Cabeza, 2007).

To further advance knowledge on the dynamics of episodic memory accuracy and the role of dlPFC activity in memory control, this study used transcranial direct current stimulation (tDCS), which induces transient polarity-specific changes in cerebral excitability via weak electric currents applied to the scalp. As initially documented in the motor system (Nitsche and Paulus, 2000), cathodal tDCS decreases and anodal stimulation increases, respectively, neuronal excitability and spontaneous firing rate by altering resting membrane potential. This technique has since been widely used to explore brain network dynamics and organization (Dayan et al., 2013), particularly concerning cognition (Kuo and Nitsche, 2012) and memory (Brasil-Neto, 2012). Moreover, tDCS enables to enhance adaptive and to ameliorate maladaptive neuroplastic processes with potentially therapeutic effects on various neuropsychiatric disorders (Kuo et al., 2014). However, the initial simple concept of "beneficial anodal" and "inhibitory cathodal" effects of tDCS has not been confirmed in the cognitive domain (Jacobson et al., 2012). Rather, it has been suggested that tDCS exerts its effects predominantly by modulating neuronal signal-to-noise ratio, with anodal tDCS increasing and cathodal tDCS decreasing noise leading to variable 


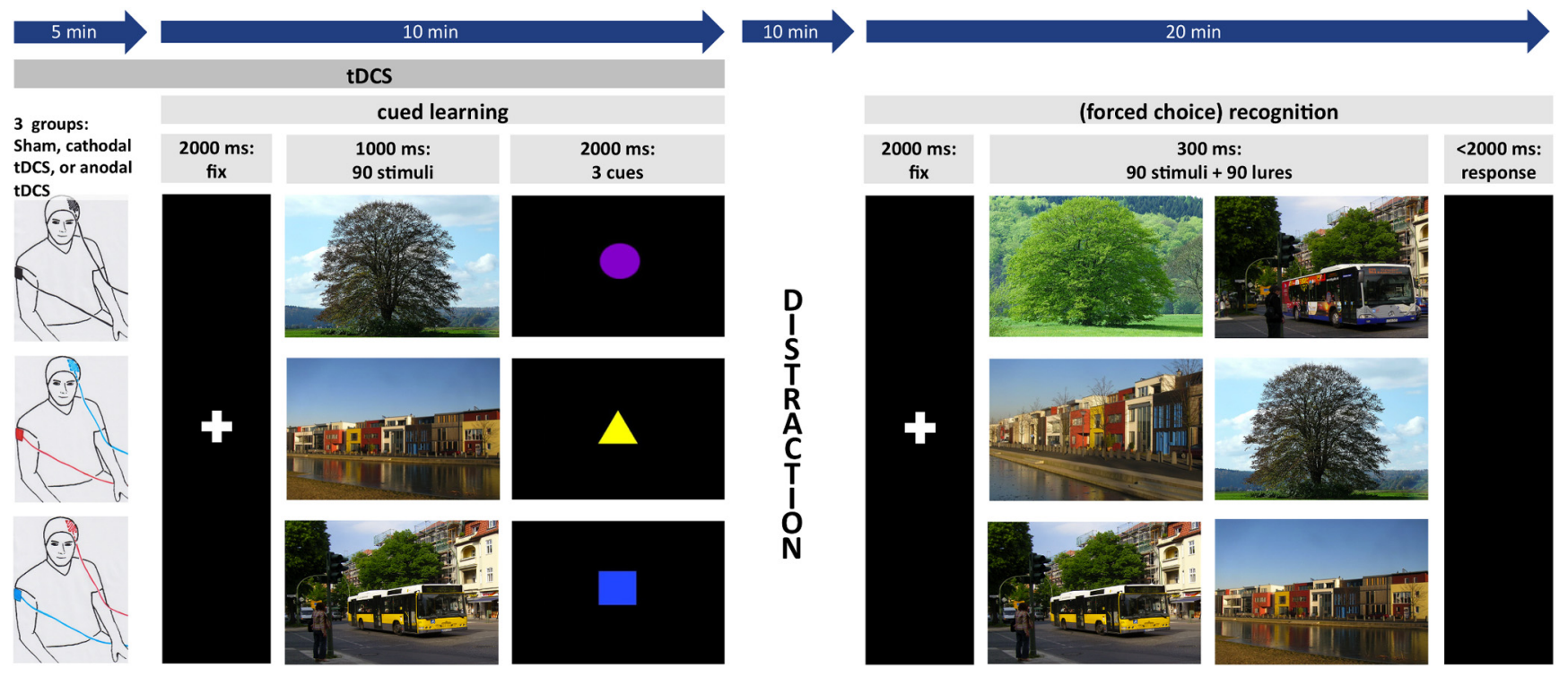

Figure 1. Experimental procedure, placement of tDCS electrodes, course of stimulus encoding/retrieval, cues, and sample pictures.

effects on cognitive performance (Antal et al., 2004; Dockery et al., 2009; Miniussi et al., 2013). Importantly, this mechanism is state-dependent, with the state of background brain activity predicting the functional relevance of noise addition or filtering by tDCS (Miniussi et al., 2013).

In this study, we apply anodal, cathodal, and sham tDCS to the left dlPFC during the presentation and encoding of images. Different postimage instructions for cognitive processing to control participants' focus within working memory (Nee and Jonides, 2009; Gazzaley and Nobre, 2012) are used to investigate the brain-state dependency of tDCS effects. With an old/new recognition task, memory accuracy is quantified by correct and false recognition rates. In sum, we sought to provide evidence for a polarity-specific malleability of memory accuracy by tDCS and its interaction with instruction-induced cognitive activity.

\section{Materials and Methods}

Participants. A total of 96 individuals ( 60 female; mean age $24.82 \pm 2.95$ years) gave written informed consent to participate in the study. The institutional ethical committee approved the protocol, and the study was conducted in compliance with the Declaration of Helsinki. Participants, who were all right-handed according to the Edinburgh Handedness Inventory (Oldfield, 1971; score $>40$ ), were randomly assigned to anodal $(n=24)$, cathodal $(n=24)$, or sham $(n=48)$ stimulation. To account for double-blindedness and all experimental variations (i.e., instruction assignment, image set assignment) under all stimulation conditions, sham controls were required for both anodal and cathodal stimulation.

Semistructured interviews were conducted to identify participants who receive frequent medical care or have psychological, psychiatric, or neurological preconditions (e.g., psychotherapy, regular medication [except contraceptives], epileptic seizures, brain injuries, implants). Individuals for whom we could not clearly rule out all of these conditions were not included in the experiment. As a consequence, one subject was excluded from the study because of a concussion after a car accident. One participant was identified as ambidextrous and therefore deselected. For nine other participants, stimulation was terminated because of high impedance ( $>5 \mathrm{k} \Omega$; as defined in the default mode of the stimulation device). Therefore, a total of 85 participants were included in the analyses (anodal: $n=24,14$ females, mean age 25.33 years; cathodal: $n=22,15$ females, mean age 24.41 years; sham: $n=39,22$ females, mean age 24.87 years). The three groups did not differ in terms of gender (Pearson's $\left.\chi^{2}(2, N=85)=0.851, p=0.654\right)$ and age $\left(F_{(2,82)}=0.656 ; p=0.521\right)$.
Participants received course credit or $3 €$ as a basic compensation and earned an additional performance-dependent bonus.

$t D C S$. Direct current was generated by a battery-driven stimulator (DC-STIMULATOR PLUS, NeuroConn) and delivered with a pair of identical $5 \times 7 \mathrm{~cm}^{2}$ rubber electrodes covered with saline-soaked sponges. Stimulation lasted $15 \mathrm{~min}$ (including a $5 \mathrm{~min}$ pretask idle time) with a current of $1 \mathrm{~mA}$, resulting in a current density of $0.028 \mathrm{~mA} / \mathrm{cm}^{2}$. Stimulation was faded in and out with a $5 \mathrm{~s}$ ramp. For all participants, the first electrode was placed on the left dlPFC (F3 according to the 10-20 EEG system of electrode placement) and fastened with a standard EEG cap, and the reference electrode was placed extracranially on the contralateral musculus deltoideus to avoid an opposite polarization in another brain area and thus ensure that tDCS effects could be traced back exclusively to stimulation of the left dlPFC (Wolkenstein and Plewnia, 2013). Sham stimulation lasted for 30 s. Predefined codes assigned to sham or verum stimulation were used to start the stimulation, allowing a double-blind study design.

Procedure. After the start of the stimulation and a 5 min idle time, participants began the learning phase of the experimental session (for illustration of experimental design, see Fig. 1). The experimenter asked participants to look closely at a randomized series of 90 neutral images (2000 ms per image) showing everyday situations and objects (which were pretested and rated in a previous study) (Zwissler et al., 2011). Different postimage instructions for cognitive processing were used to investigate the brain-state dependency of tDCS effects on memory accuracy: an active learning condition, as well as an active (Wylie et al., 2008) and an inactive control condition. More concretely, each image was followed by one of three symbolic, single-colored cues (2000 ms per cue; circle, triangle, or square). Two cues were instructed as relevant to successful task performance (active conditions), with one meaning "remember the preceding image" (R) and the other meaning "forget the preceding image" (F). The third cue (passive condition) was not further commented on ("irrelevant," I). If participants did not understand the instruction, the experimenter repeated that relevant cues should be focused on. Assignment of cue color, shape, and meaning was randomized and balanced across stimulation conditions. After the learning phase, participants were asked to perform a distractive attention test ("d2"; Brickenkamp, 1994) to prevent further elaboration on stimuli from the learning phase.

The " $\mathrm{d} 2$ " (including its instructions) and the instructions for the old/ new recognition phase took $11 \mathrm{~min}$. Previously seen images were intermingled with new, individually matched distracter images that differed from the original images in detail but not in central aspects (i.e., gist). Participants were told that they should try to accurately identify ALL 
a

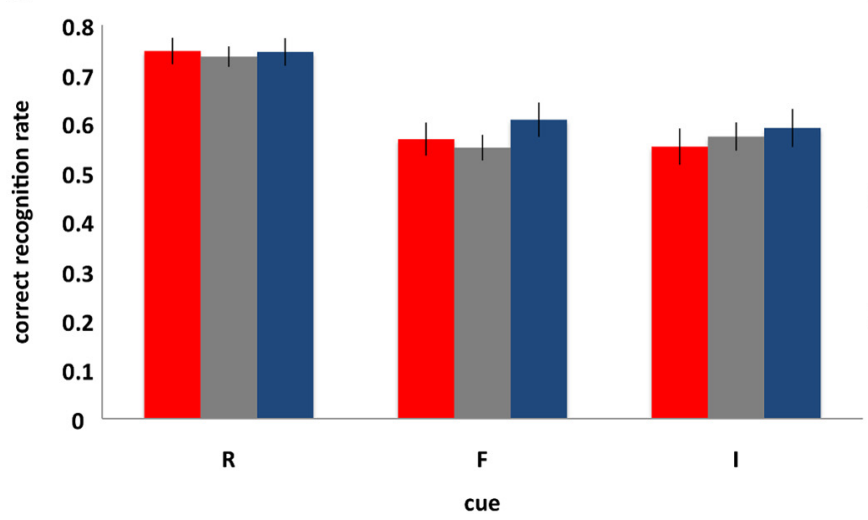

b

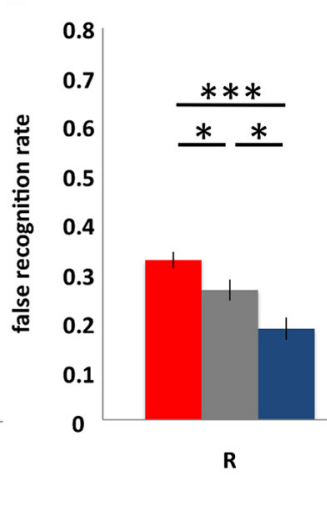

- Anodal

Sham

Cathodal

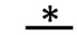

Figure 2. $\quad \boldsymbol{a}$, Correct recognition rates across groups and instructions. $\boldsymbol{b}$, False alarm rates across groups and instructions. Error bars indicate $S E M$. $R$, pictures instructed to remember; $F$, pictures instructed to forget; I, pictures designated as irrelevant. Error bars indicate SE. ${ }^{*} p<0.05 .{ }^{* *} p<0.01 .{ }^{* * *} p<0.001$.

previously seen images regardless of their original instruction. Furthermore, they would earn $0.2 €$ for each correctly recognized image but would lose the $0.2 €$ for each incorrectly recognized image. Therefore, perfect performance could result in a maximum of $18 €(90 \times 0.2 €)$. This procedure served to reinforce recognition accuracy and discourage guessing. The 90 images presented during the learning phase and 90 new, individually matched, and highly similar distracter images were displayed in a randomized order. Each image was shown for $300 \mathrm{~ms}$, and participants were instructed to decide as quickly as possible whether they had previously seen the image. Although fast responses were encouraged, there was no time limit. After a response was given, a fixation cross was presented for $700 \mathrm{~ms}$ before the next image appeared. Experimental material was presented on a desktop computer (HP Compaq dc 7600) using Presentation Software (Neurobehavioral Systems).

Statistics. Statistical analysis was performed using SPSS version 20.0 software (SPSS; www.spss.com). Data were tested for normal distribution (Shapiro-Wilk test) and sphericity (Mauchly's test). Normal distribution was confirmed for all data, but there were a few expected violations to sphericity that were corrected using Greenhouse-Geisser adjustments. Analyses were performed using repeated-measures

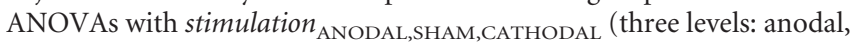
sham, cathodal) as a between-participants factor and instruction ${ }_{\mathrm{R}, \mathrm{F}, \mathrm{I}}$ (three levels: remember, forget, irrelevant) as a within-participants factor, yielding a $3 \times 3$ matrix. Significant interaction effects were followed up by one-way ANOVAs. Because of experimental groups of different sizes, post hoc Student's $t$ tests were calculated using the Sidak correction for multiple comparisons. An $\alpha$ level of 0.05 was used for all statistical tests.

\section{Results}

Correct and false recognition patterns (Fig. $2 a, b$ ) indicate that the effect of tDCS on memory accuracy is the result of the modulation of false recognition. For correct recognition (Fig. $2 a$ ), only a main effect of instruction $_{\mathrm{R}, \mathrm{F}, \mathrm{I}}\left(F_{(2,164)}=61.92 ; p<0.001 ; \eta^{2}=\right.$ 0.43 ) was found, replicating the classic directed forgetting

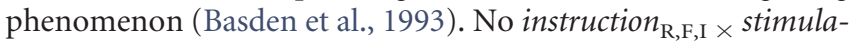
tion $_{\text {ANODAL,SHAM,CATHODAL }}$ interaction $\left(F_{(4,164)}=0.55, p=0.68\right.$; $\eta^{2}=0.01$ ) was observed.

By contrast, for false recognition (i.e., identifying an image not previously seen as "old"; Fig. $2 b$ ), we found main effects of both stimulation ANODAL,SHAM,CATHODAL $\left(F_{(2,82)}=7.01, p<0.01\right.$; $\left.\eta^{2}=0.15\right)$ and instruction $_{\mathrm{R}, \mathrm{F}, \mathrm{I}}\left(F_{(2,164)}=29.86, p<0.001 ; \eta^{2}=\right.$ $0.26)$, with $F$ lures yielding significantly less false alarms than both R $(p<0.001$; Cohen's $\mathrm{d}=0.74)$ and I $(p<0.001$; Cohen's $\mathrm{d}=0.98)$ lures, which, in turn, did not differ ( $p=0.42$; Cohen's $\mathrm{d}=0.17)$. More importantly, there was also an interaction of instruction $_{\mathrm{R}, \mathrm{F}, \mathrm{I} \times}$ stimulation $_{\mathrm{ANODAL}, \mathrm{SHAM}, \mathrm{CATHODAL}}\left(F_{(4,164)}=\right.$
2.81, $p<0.05 ; \eta^{2}=0.06$ ) (Fig. $2 b$ ). The effect of tDCS on false recognition was most prominent in images instructed to-beremembered $\left(\mathrm{R}\right.$; stimulation $\mathrm{A}_{\mathrm{NODAL}, \mathrm{SHAM}, \mathrm{CATHODAL}}: F_{(2,82)}=$ $\left.10.14, p<0.001 ; \eta^{2}=0.20\right)$. Cathodal stimulation led to less false recognition than sham $(p<0.05$; Cohen's $d=0.72)$ or anodal ( $p<0.001$; Cohen's $\mathrm{d}=1.33)$ stimulation, and anodal stimulation led to more false recognition than sham stimulation $(p<0.05$; Cohen's $\mathrm{d}=0.61)$. In images instructed to-beforgotten (F; stimulation ANODAL,SHAM,CATHODAL $_{(2,82)}=3.42$, $\left.p<0.05 ; \eta^{2}=0.08\right)$, anodal stimulation led to more false recognition than sham stimulation $(p<0.05$; Cohen's $\mathrm{d}=$ $0.67)$, but there were no differences between cathodal and $\operatorname{sham}(p=0.98)$ or cathodal and anodal $(p=0.17)$ stimulation. No modulatory tDCS effects were found in irrelevant images (I; stimulation ANODAL,SHAM,CATHODAL $F_{(2,82)}=1.31$, $\left.p=0.28 ; \eta^{2}=0.03\right)$.

Importantly, there was no effect of stimulation $_{\text {ANODAL,SHAM,CATHODAL }}$ on acquiescence bias (i.e., proportion of "yes" responses) (anodal, $0.45 \pm 0.07$; sham, $0.43 \pm 0.08$; cathodal, $\left.0.43 \pm 0.09 ; F_{(2,82)}=0.89, p=0.42 ; \eta^{2}=0.02\right)$. Moreover, tDCS did not affect reaction times for correct recognition (anodal, $1183.01 \pm 37.77 \mathrm{~ms}$; sham, $1156.13 \pm 29.63 \mathrm{~ms}$; cathodal, $\left.1201.26 \pm 39.44 \mathrm{~ms} ; F_{(2,82)}=0.45, p=0.64 ; \eta^{2}=0.01\right)$ or false recognition (anodal, $1260.50 \pm 47.21 \mathrm{~ms}$; sham, $1266.47 \pm$ $37.52 \mathrm{~ms}$; cathodal, $1330.79 \pm 49.31 \mathrm{~ms} ; F_{(2,82)}=0.68, p=0.51$; $\left.\eta^{2}=0.02\right)$.

There was no effect of stimulation ANODAL,SHAM,CATHODAL $_{\text {on }}$ the performance in the attention test $\left(F_{(2,82)}=0.56, p=0.57\right.$; $\left.\eta^{2}=0.01\right)$.

\section{Discussion}

The present findings are the first evidence of a polarity-specific, activity-dependent malleability of memory accuracy by tDCS of the left dlPFC. They add substantially to the understanding of the functional neuroanatomy and neuronal processes underlying memory accuracy, the feasibility and conditions of tDCS effects on episodic memory, and the critical role of brain activation state in the outcome of tDCS interventions.

However, some limitations of this study should be considered. First, these findings are limited to pictorial episodic information. Although these results may transfer to verbal and semantic information, this would need to be demonstrated by future studies. Second, the topographic specificity of tDCS is relatively low, and potential remote effects of stimulation have to be taken into ac- 
count. Although we aimed for a stimulation of the dlPFC, the size of the stimulating electrode $\left(35 \mathrm{~cm}^{2}\right)$ and individual variations in anatomy do not rule out that adjacent areas of the left frontal cortex were also affected by the stimulation. Moreover, transsynaptic effects of tDCS involving connected brain areas have also been described (Lang et al., 2005; Chib et al., 2013). In particular, it is conceivable that tDCS may modulate the influence of the left dIPFC on remote brain regions (e.g., the medial temporal lobe) that are actually responsible for encoding episodic memories (Reber et al., 2002). However, previous tDCS studies on executive control functions (Priori et al., 2008; Wolkenstein and Plewnia, 2013) have shown that the extracephalic localization of the reference electrode limiting the direct stimulation of other cortical areas is effective. Third, tDCS effects outlasting the concurrent stimulation and encoding phase may have also affected memory retrieval. However, modulation of accuracy was most prominent on items that received the "remember" instruction and thus should have most likely taken place in the encoding phase. Nevertheless, it could be conceivable that the likelihood of identifying a new image as old was also influenced by interactions of prolonged tDCS effects and memories of different strength. Therefore, the effects of tDCS on memory accuracy cannot be attributed unambiguously to the encoding phase alone. Nonetheless, a direct interaction between tDCS and memory encoding is most likely because it does not require to assume tDCS effects that outlast the attention test to interact differentially with memory traces established according to the specific encoding instruction.

In general, the present results suggest that the modulation of neuronal excitability in the left prefrontal cortex interferes with the regulation of memory encoding. It is important to note that the effects were induced not only in the presence of stimuli but particularly during their maintenance in working memory (Gazzaley and Nobre, 2012). In our study, memory encoding took place in the absence of the images dependent to the cues presented after the stimulus. These retro-cues have been shown to interact with memory encoding by reducing memory load (Duarte et al., 2013). It is most likely that the different instructions initiate different encoding processes involving more or less elaborated rehearsal (Goodwin, 2007) of the presented pictures. Selective rehearsal of stimuli has been suggested to be a relevant mechanism of memory control, particularly by improving discrimination accuracy of verbal and nonverbal material (Greene, 1987; Hourihan et al., 2009; Zwissler et al., 2011). Semantic elaboration (i.e., the integration of new information with semantic knowledge) not only enhances episodic memory by involving the left prefrontal cortex (Staresina et al., 2009) but also increases the probability of falsely remembering previously unpresented associates (Kim and Cabeza, 2007). The critical interaction of elaborative cognitive processing and stimulation for memory formation has been recently shown with repetitive transcranial magnetic stimulation during memory encoding (Hawco et al., 2013). High-strategy users showed reduced performance after dIPFC stimulation, whereas low-strategy users tended to show increased recall after dlPFC stimulation. However, the present data do not allow for a differentiation between specific encoding processes and their interaction with tDCS.

Notably, the polarity-specific alteration of false memory rate demonstrates the feasibility of directed modulation of memory accuracy by tDCS. Contrary to the simple mechanistic concept of anodal stimulation as activity-enhancing and thus beneficial, we found that anodal stimulation decreased and cathodal stimulation increased memory accuracy, respectively, by opposing mod- ulations of false recognition rates. It has been proposed that the modulation of neuronal excitability by tDCS is associated with increases (anodal) or decreases (cathodal) in the amount of noise in the stimulated structures (Antal et al., 2004; Dockery et al., 2009; Miniussi et al., 2013). In the present study, the reduction of noise by cathodal tDCS may have increased participants' focus on information encoded during stimulation (Weiss and Lavidor, 2012), leading to inhibited formation of false memory traces and improved encoding of image details that are less likely to be activated by images with similar gist. By contrast, anodal tDCS may have enhanced and further spread brain activity associated with image processing by adding noise during memory encoding, resulting in less precise memories and thus a greater false recognition rate.

In this context, it is important to consider that the instruction to forget the presented image primarily led to a decreased falsememory rate independent of stimulation (Fig. $2 b$ ). This points toward an activation of inhibitory processes, particularly because related lures of stimuli designated as irrelevant were more often wrongly recognized as "old." With anodal tDCS, this effect has been counteracted, suggesting that additional activation to the left prefrontal cortex interferes with a mechanism inhibiting memory encoding susceptible for distortions. In turn, cathodal stimulation associated with the instruction "forget" did not yield a further inhibition of memory formation prone for errors, perhaps because of a floor effect. However, it has to be recognized that, despite a clear polarity-specific modulation of false recognition, neither anodal nor cathodal stimulation exerted any effects on correct recognition. Future studies might test whether, as it seems, the threshold for stimulation effects differs for correct and false recognition.

Finally, our finding that the modulatory effect of tDCS was most prominent in the $\mathrm{R}$ condition, less prominent in the $\mathrm{F}$ condition, and absent in the I condition, underscores the critical interaction of brain stimulation effects on ongoing brain activity (Dockery et al., 2009; Andrews et al., 2011; Bikson et al., 2013). It can be assumed that the instruction to remember and, to a lesser extent the instruction to forget, activated specific encoding strategies associated with the activation of the left dIPFC. Apparently, enhanced activity in this network made it preferentially sensitive to modulation by tDCS as indicated by larger effects on memory accuracy (Bikson et al., 2013). Therefore, the present data support the concept of metaplasticity based on dynamic interactions between the level of activation in memory-encoding networks (as modified by tDCS in the present study) and concurrent behavior (e.g., memory encoding) (Floel and Cohen, 2007; Finnie and Nader, 2012).

Together, our findings (1) provide new evidence for the critical role of the left PFC in the functional neuroanatomy of false memory, (2) demonstrate the polarity-specific malleability of memory accuracy by anodal and cathodal tDCS, (3) exemplify the state dependency of brain stimulation effects in the cognitive domain, and (4) open new perspectives for the investigation and potential treatment of disorders associated with deficits in memory control.

\section{References}

Andrews SC, Hoy KE, Enticott PG, Daskalakis ZJ, Fitzgerald PB (2011) Improving working memory: the effect of combining cognitive activity and anodal transcranial direct current stimulation to the left dorsolateral prefrontal cortex. Brain Stimul 4:84-89. CrossRef Medline

Antal A, Nitsche MA, Kruse W, Kincses TZ, Hoffmann KP, Paulus W (2004) Direct current stimulation over V5 enhances visuomotor coordination by 
improving motion perception in humans. J Cogn Neurosci 16:521-527. CrossRef Medline

Basden BH, Basden DR, Gargano GJ (1993) Directed forgetting in implicit and explicit memory tests: a comparison of methods. J Exp Psychol Learn Mem Cogn 19:603-616. CrossRef

Bikson M, Name A, Rahman A (2013) Origins of specificity during tDCS: anatomical, activity-selective, and input-bias mechanisms. Front Hum Neurosci 7:688. CrossRef Medline

Brainerd CJ, Reyna VF (2005) The science of false memory. New York: Oxford UP.

Brasil-Neto JP (2012) Learning, memory, and transcranial direct current stimulation. Front Psychiatry 3:80. CrossRef Medline

Brickenkamp R (1994) Test d2: Aufmerksamkeits-Belastungs-Test. 8th expanded and revised edition. Göttingen, Germany: Hogrefe.

Chib VS, Yun K, Takahashi H, Shimojo S (2013) Noninvasive remote activation of the ventral midbrain by transcranial direct current stimulation of prefrontal cortex. Transl Psychiatry 3:e268. CrossRef Medline

Dayan E, Censor N, Buch ER, Sandrini M, Cohen LG (2013) Noninvasive brain stimulation: from physiology to network dynamics and back. Nat Neurosci 16:838-844. CrossRef Medline

Dockery CA, Hueckel-Weng R, Birbaumer N, Plewnia C (2009) Enhancement of planning ability by transcranial direct current stimulation. J Neurosci 29:7271-7277. CrossRef Medline

Duarte A, Hearons P, Jiang Y, Delvin MC, Newsome RN, Verhaeghen P (2013) Retrospective attention enhances visual working memory in the young but not the old: an ERP study. Psychophysiology 50:465-476. CrossRef Medline

Finnie PS, Nader K (2012) The role of metaplasticity mechanisms in regulating memory destabilization and reconsolidation. Neurosci Biobehav Rev 36:1667-1707. CrossRef Medline

Floel A, Cohen LG (2007) Contribution of noninvasive cortical stimulation to the study of memory functions. Brain Res Rev 53:250-259. CrossRef Medline

Gazzaley A, Nobre AC (2012) Top-down modulation: bridging selective attention and working memory. Trends Cogn Sci 16:129-135. CrossRef Medline

Goodwin KA (2007) Dissociative effects of true and false recall as a function of different encoding strategies. Memory 15:93-103. CrossRef Medline

Greene RL (1987) Effects of maintenance rehearsal on human memory. Psychol Bull 102:403-413. CrossRef

Hawco C, Berlim MT, Lepage M (2013) The dorsolateral prefrontal cortex plays a role in self-initiated elaborative cognitive processing during episodic memory encoding: rTMS evidence. PLoS One 8:e73789. CrossRef Medline

Hourihan KL, Ozubko JD, MacLeod CM (2009) Directed forgetting of visual symbols: evidence for nonverbal selective rehearsal. Mem Cognit 37:1059-1068. CrossRef Medline

Jacobson L, Koslowsky M, Lavidor M (2012) tDCS polarity effects in motor and cognitive domains: a meta-analytical review. Exp Brain Res 216:1-10. CrossRef Medline

Kim H, Cabeza R (2007) Differential contributions of prefrontal, medial temporal, and sensory-perceptual regions to true and false memory formation. Cereb Cortex 17:2143-2150. CrossRef Medline

Kubota Y, Toichi M, Shimizu M, Mason RA, Findling RL, Yamamoto K, Calabrese JR (2006) Prefrontal hemodynamic activity predicts false memory: a near-infrared spectroscopy study. Neuroimage 31:1783-1789. CrossRef Medline

Kuo MF, Nitsche MA (2012) Effects of transcranial electrical stimulation on cognition. Clin EEG Neurosci 43:192-199. CrossRef Medline

Kuo MF, Paulus W, Nitsche MA (2014) Therapeutic effects of non-invasive brain stimulation with direct currents (tDCS) in neuropsychiatric diseases. Neuroimage 85:948-960. CrossRef Medline

Lang N, Siebner HR, Ward NS, Lee L, Nitsche MA, Paulus W, Rothwell JC, Lemon RN, Frackowiak RS (2005) How does transcranial DC stimulation of the primary motor cortex alter regional neuronal activity in the human brain? Eur J Neurosci 22:495-504. CrossRef Medline

Miniussi C, Harris JA, Ruzzoli M (2013) Modelling non-invasive brain stimulation in cognitive neuroscience. Neurosci Biobehav Rev 37:17021712. CrossRef Medline

Nee DE, Jonides J (2009) Common and distinct neural correlates of perceptual and memorial selection. Neuroimage 45:963-975. CrossRef Medline

Nitsche MA, Paulus W (2000) Excitability changes induced in the human motor cortex by weak transcranial direct current stimulation. J Physiol 527:633-639. CrossRef Medline

Oldfield RC (1971) The assessment and analysis of handedness: the Edinburgh inventory. Neuropsychologia 9:97-113. CrossRef Medline

Payne JD, Jackson ED, Ryan L, Hoscheidt S, Jacobs JW, Nadel L (2006) The impact of stress on neutral and emotional aspects of episodic memory. Memory 14:1-16. CrossRef Medline

Priori A, Mameli F, Cogiamanian F, Marceglia S, Tiriticco M, Mrakic-Sposta S, Ferrucci R, Zago S, Polezzi D, Sartori G (2008) Lie-specific involvement of dorsolateral prefrontal cortex in deception. Cereb Cortex 18:451455. CrossRef Medline

Reber PJ, Wong EC, Buxton RB (2002) Comparing the brain areas supporting nondeclarative categorization and recognition memory. Brain Res Cogn Brain Res 14:245-257. CrossRef Medline

Rossi S, Innocenti I, Polizzotto NR, Feurra M, De Capua A, Ulivelli M, Bartalini S, Cappa SF (2011) Temporal dynamics of memory trace formation in the human prefrontal cortex. Cereb Cortex 21:368-373. CrossRef Medline

Schacter DL, Addis DR (2007) The cognitive neuroscience of constructive memory: remembering the past and imagining the future. Philos Trans $\mathrm{R}$ Soc Lond B Biol Sci 362:773-786. CrossRef Medline

Schacter DL, Slotnick SD (2004) The cognitive neuroscience of memory distortion. Neuron 44:149-160. CrossRef Medline

Staresina BP, Gray JC, Davachi L (2009) Event congruency enhances episodic memory encoding through semantic elaboration and relational binding. Cereb Cortex 19:1198-1207. CrossRef Medline

Weiss M, Lavidor M (2012) When less is more: evidence for a facilitative cathodal tDCS effect in attentional abilities. J Cogn Neurosci 24:18261833. CrossRef Medline

Wolkenstein L, Plewnia C (2013) Amelioration of cognitive control in depression by transcranial direct current stimulation. Biol Psychiatry 73 : 646-651. CrossRef Medline

Wylie GR, Foxe JJ, Taylor TL (2008) Forgetting as an active process: an FMRI investigation of item-method-directed forgetting. Cereb Cortex 18:670-682. CrossRef Medline

Zwissler B, Koessler S, Engler H, Schedlowski M, Kissler J (2011) Acute psycho-social stress does not disrupt item-method directed forgetting, emotional stimulus content does. Neurobiol Learn Mem 95:346-354. CrossRef Medline 